\title{
Study a sequence of processing craftwork decision-making base on constraint ma- trix and genetic algorithm
}

\author{
WANG Gang ${ }^{1}$ WEI Yong-fu ${ }^{2}$ \\ ${ }^{1}$ School of Arts Foundation Qingdao Binhai College, Qingdao 266555 \\ ${ }^{1}$ Liuzhou Special Equipment Supervision and Inspection Institute, Liuzhou 545006
}

\begin{abstract}
In order to solve the problem of the order of processing technology in CAPP, which proposes a method of intelligent decisionmaking process base on constraint matrix and genetic algorithm, establishes the mathematical model of the order of processing technology based on genetic algorithm, uses constraint matrix to describe processing technology prior relation between the processing units. Studies of the order of decision-making processing technology base on genetic algorithm. In the final, this system use in $\mathrm{CH}$ as development language, it has been developed successfully the process decision-making system module and it is verified the feasibility of this method by sample.
\end{abstract}

Key words: Constraint matrix; Genetic algorithm; The order of processing craftwork decision-making Introduction

\section{Computer Aided Process Planning} (Computer Aided Process Planning, CAPP) is the manufacturing method using computer technology-assisted processes to design parts from rough to finished product and the technology that enterprise product design data converted to product manufacturing data. Process decision is usually divided into the decision-making method and craft processing sequence decision-making, which in the case of clear the characteristics of parts surface processing method of processing route optimization decisions, so that in meet certain processing constraints to order processing arrangements reasonable and try to improve the processing efficiency ${ }^{[1]}$. The traditional crafts processing order of decision-making based on the general laws of the process, using of linear programming methods for the processing order of the decision-making, this may lead to some of the original optional process route program is discarded prematurely in the early of process planning or the route process scheme is not optimal finally due to excessive of process constraint problems in late. Therefore, the processed sequential decision is one of the key issues needs to solve in process planning system.

\section{1. mechanism of the process decision- making}

\subsection{Introduction to Genetic Algorithms}

The genetic algorithm is an optimization algorithm based on the "survival of the fittest", through "chromosome" group evolving eventually from generation to generation and converge to the individual of "the best adapted to the environment" and to find the optimal solution of the problem $^{[2]}$. Processed order decisionmaking flow chart based on genetic algorithm shown in Figure 1. 


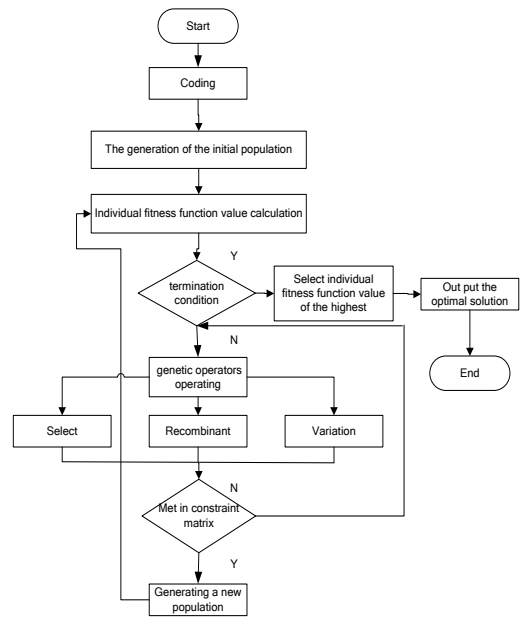

Fig. 1 The flow diagram based on GA's order decision-making process

\section{2 generation of constraint matrix}

If it has $\mathrm{N}$ processing in $\mathrm{g}$ a processing parts, then define the adjacency matrix of order $\mathrm{N}$ to represents a precedence constraint relationship between the content of these processing, that is constraint matrix. Assume the constraint relationship between processing ${ }^{[3]}$ :

$$
R=\left[\begin{array}{cccc}
R_{11} & R_{12} & \ldots & R_{1 N} \\
R_{21} & R_{22} & \ldots & R_{2 N} \\
\vdots & \vdots & \vdots & \vdots \\
R_{N 1} & R_{N 2} & \cdots & R_{N N}
\end{array}\right]
$$

Where i, j $=1,2, \ldots$, N. $R_{i j}$ represents the constraint relationship between the $i$ processing content and the $\mathrm{j}$ processing, conversion rules for:

(1) When the i machining content first in the $\mathrm{j}$ processing content, $R_{i j}=1$,

$$
R_{j i}=0 ;
$$

(2) Other case $R_{i j}=R_{j i}=0$.

\section{3 mathematical model of processing sequential decision}

Provided that a process route as $\mathrm{X}=\left\{O_{1}^{\prime}, O_{2}^{\prime}, \ldots, O_{n}^{\prime} \quad\right\}, \quad$ where$\operatorname{in}\left\{O_{1}^{\prime}, O_{2}^{\prime}, \ldots, O_{n}^{\prime}\right\}=\left\{O_{1}, O_{2}, \ldots, O_{n}\right\}$, that is the elements of the processing elements in the two sets is the same. The constraint condition denoted as: $\mathrm{R}=\left\{R_{1}, R_{2}, \ldots, \mathrm{R}_{\mathrm{n}}\right\}$. The problem using mathematical programming model is described as follows ${ }^{[4]}$.

$$
\left\{\begin{array}{c}
\max F=f(X) \\
\text { s.t. } X \in R^{n} \\
R^{n} \in \Omega
\end{array}\right.
$$

Therefore, the mathematical model of sequential decision processing technology can be described as: for a machining parts, find a processing sequence feasible solution $\mathrm{X}$ and meet the process precedence relationships set of constraints $R^{n}$ in a given process sequence $\Omega$, so that the objective function to achieve optimal, that $\max F$.

\section{2. processing sequential decision- making process based on genetic algorithms}

\section{1 gene coding $^{[5]}$}

Using natural number coding is the most effective for the processed sequential decision. A processing parts consists of $n$ processing element (processing method), then on each chromosome contains $\mathrm{n}$ genes, that $G=\left\{G_{1}, G_{2}, \ldots, G_{i}, \ldots, G_{\mathrm{n}}\right\}$. Each gene is by six parts, that $G_{i}=$ ( processing element number, characteristic element code, processing method code, machine code, the tool code, the fixture code ).

\subsection{Initial population generation}

The most critical of generation of the initial population is to set the size of the population size, that the number of chromosomes. The number of chromosomes is randomly generated and it based on ex- 
periment and experience, the general value of tens to hundreds ${ }^{[6]}$.

\subsection{The fitness function design}

The fitness function design is the sole basis of genetic manipulation in Genetic algorithm. Between conversion cost / time in each processing element is mainly decision by the machine conversions frequency $M_{c}$ 、 tool conversions frequency $T_{c}$ and fixture conversions frequency $S_{c}$. Therefore, this paper makes the smallest weighted value as optimization objective to achieve processing sequential decision.

(1) Machine normalized conversion formula

Assumed the number of processing element is $\mathrm{n}$ for the processing parts, and the collection of all machine is $\mathrm{M}$, scilicet

$$
M=\left\{M_{1}, M_{2}, \cdots, M_{m}\right\}
$$

Obviously, the number of conversions of the machine $M_{c}$ has a maximum value $\operatorname{Max}\left(M_{c}\right)=\mathrm{n}$ and the minimum value $\operatorname{Min}\left(M_{c}\right)=\mathrm{m}$. Normalization the number of machine conversions $M_{c}$ :

$$
f\left(M_{c}\right)=\frac{\operatorname{Max}\left(M_{c}\right)-M_{c}}{\operatorname{Max}\left(M_{c}\right)-\operatorname{Min}\left(M_{c}\right)}=\frac{n-M_{c}}{n-m}
$$

(2) Tool normalized conversion formula

Assumed the number of processing element is $\mathrm{n}$ for the processing parts, and the collection of all tool is $\mathrm{T}$, scilicet

$$
T=\left\{T_{1}, T_{2}, \cdots, T_{t}\right\}
$$

Obviously, the number of conversions of the tool $T_{c}$ has a maximum value $\operatorname{Max}\left(T_{c}\right)=\mathrm{n}$ and the minimum value $\operatorname{Min}\left(T_{c}\right)=\mathrm{t}$. Normalization the number of tool conversions $T_{c}$ :

$$
f\left(T_{c}\right)=\frac{\operatorname{Max}\left(T_{c}\right)-T_{c}}{\operatorname{Max}\left(T_{c}\right)-\operatorname{Min}\left(T_{c}\right)}=\frac{n-T_{c}}{n-t}
$$

(3)Fixture normalized conversion formula

Assumed the number of processing element is $\mathrm{n}$ for the processing parts, and the collection of all fixture is $\mathrm{S}$, scilicet

$$
S=\left\{S_{1}, S_{2}, \cdots, S_{s}\right\}
$$

Obviously, the number of conversions of the fixture $S_{c}$ has a maximum value $\operatorname{Max}\left(S_{c}\right)=\mathrm{n}$ and the minimum value Min $\left(S_{c}\right)=\mathrm{s}$. Normalization the number of fixture conversions $S_{c}$ :

$f\left(S_{c}\right)=\frac{\operatorname{Max}\left(S_{c}\right)-S_{c}}{\operatorname{Max}\left(S_{c}\right)-\operatorname{Min}\left(S_{c}\right)}=\frac{n-S_{c}}{n-s}$

In order to better express the relationship between these three with processed sequential decision, this paper design the fitness function as follows:

$$
F=f(x)=w_{1} \times f\left(M_{c}\right)+w_{2} \times f\left(T_{c}\right)+w_{3} \times f\left(S_{c}\right)
$$

Where $w_{1}, w_{2}, w_{3}$ represent respectively the weight coefficient of the number of machine conversions $M_{c}$, the number of tool changer $T_{c}$, the number of fixture conversions $S_{c}$. Solving the weight coefficient can obtain AHP, and its value is: $w_{1}=0.67, w_{2}=0.09$, $w_{3}=0.24$. Therefore, the fitness function of the formula (9) can be written as ${ }^{[7]}$ :

$$
F=f(x)=0.67 \times f\left(M_{c}\right)+0.09 \times f\left(T_{c}\right)+0.24 \times f\left(S_{c}\right)
$$

\subsection{Select}

This paper uses fitness proportional method to select operation, concrete steps are as follows ${ }^{[8]}$.

(1) Assuming the individual $x_{i}$ fitness function values is $f_{i}$, to thereby calculate 
the probability of selection of each individual $p_{i}=\frac{f_{i}}{\sum_{i=1}^{n} f_{i}}$;

(2) In accordance the value of individual choice probability $p_{i}$ to arrangement individual from largest to smallest, the first individual select two and individual choice once ranked in the middle and at the back of the individual does not choose according to a certain proportion.

\subsection{Recombinant}

Genetic recombination is also called the crossover operation, the paper makes in the following manner to recombinant gene $^{[9][10]}$, as shown in Figure 2.

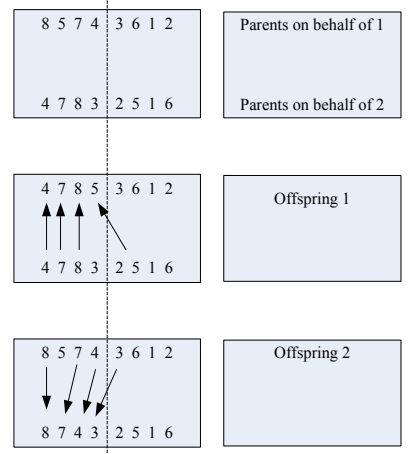

Fig. 2 The schemes of gene recombinant

\subsection{Variability}

The variation is to change the value of the operation of certain gene locus in the chromosome according to a certain mutation probability $\mathrm{Pm}$, the process shown in Figure 3.

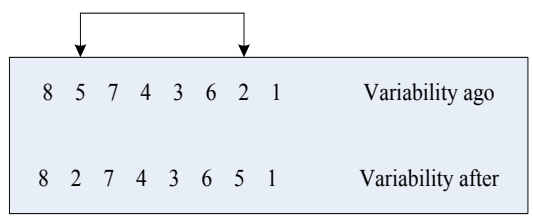

Fig. 3 The schemes of gene mutation

\section{System running instance}

A stepped shaft as example to details of the running of the system, and the parts are shown in Figure 4.
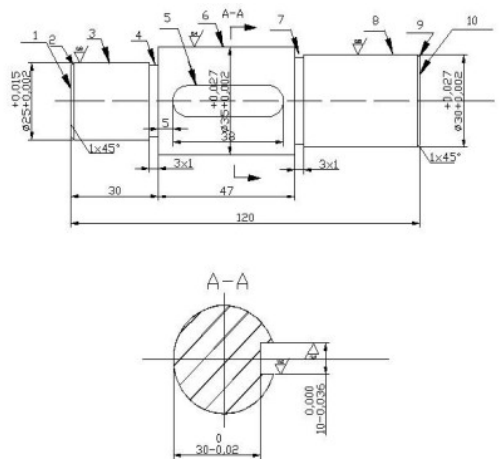

Fig.4 Ladder axis part figure

The figure shows that the part composed by 10 feature element, its gene encoding shown in Schedule 1.

Gene encoding completed into the process constraint relations interface, as shown in Figure 5.

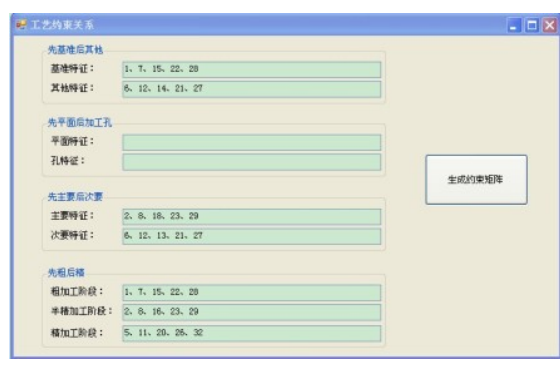

Fig. 5 The interface of process constraint relation

Enter the appropriate operating parameters in the processed sequential decision-making interface according to the actual situation, and then click on the "run" button and it will output processed order line on the optimal, as shown in Figure 6. 


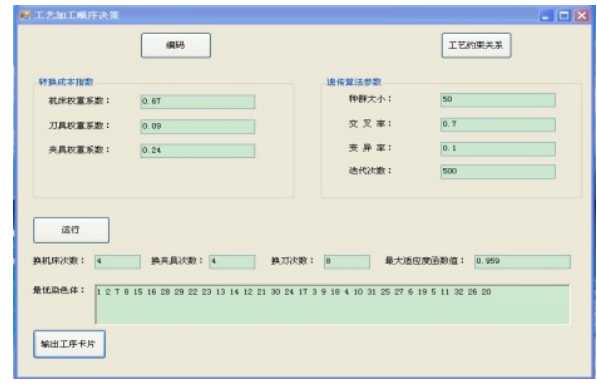

Fig. 6 Craft processing order decisions

Seen from Figure 6, the machine converted 4 times, the number of conversion tool is 8 times, fixture converted 4 times, the fitness function value $F$ is 0.959 , it reduces production cost and production cycle.

\section{Conclusions}

This paper processed sequential decision method based on genetic algorithm, established a mathematical model of the process decision, studied its operations, and the use of the constraint matrix to describe the precedence constraint relationships between each processing element, and finally using of specific examples to verify the validity and rationality of this method with the lowest production costs as the objective function. However, the characteristic element of the division needs a good recognition of the part feature, generating each processing chain of feature element requires a lot of process knowledge for knowledge representation, and these two issues will be the mainly direction of our future research.

\section{References}

[1] Tian Ying, Jing Pingyu, Zhou Guanghui. Research the parts multiple process and decision-making method based on ant colony algorithm [J]. Computer Integrated Manufacturing Systems, 2006, 12 (6):882-887

[2] Du Sanmei. Applied research shop scheduling system based on genetic algorithm [D]. Nanning: Guangxi University, 2009

[3] Hu Yujin, Zhang zhengyi, Ling ling,etc. Based the process constraint matrix processing sequence optimization [J]. Chinese Mechanical Engineering, 2009, 20 (7):1062-1066.

[4] Reynolds. David, Gomatam. Jagannathan. Stochastic modeling of Genetic Algorithms. Artificial Intelligence, 1999, 4: 303-330

[5] Mayer.MK A Network Parallel Genetic Algorithm for the One Machine Sequencing Problem. Computers \& Mathematics with Applications, 1999, 2: 71-78

[6] Inman Harvey. The Microbial Genetic Algorithm [J]. Lecture Notes in Computer Science, 2011, 5778: 126133

[7] Yuan Qing. aero structures process feature-based decision-making technology [D]. Nanjing: Nanjing University of Aeronautics and Astronautics, 2010

[8] Yin Zhaoqing. Artificial intelligence methods and applications[M]. Wuhan: Huazhong University of Science and Technology Press, 2007

[9] Xu Zheng. Dimensional CAPP parts in feature extraction process based on genetic algorithm sorting of [D]. Wuhan: Huazhong University of Science and Technology, 2005

[10] Meng Qingzhi. Key technology of intelligent CAPP system[D]. Qinhuangdao: The Yanshan University, 2010 


\section{Schedule 1 Genetic encoding}

\begin{tabular}{|c|c|c|c|c|c|}
\hline $\begin{array}{c}\text { The } \\
\text { processing } \\
\text { element No. }\end{array}$ & $\begin{array}{c}\text { characteristic } \\
\text { element }\end{array}$ & $\begin{array}{l}\text { processing me- } \\
\text { thod }\end{array}$ & machine code & tool code & fixture code \\
\hline 1 & \multirow{5}{*}{1 End face $A_{1}$} & Rough & 1Lathe & 6Facing tool & 4Lathefixture \\
\hline 2 & & Semi-intensive car & 1Lathe & 6Facing tool & 4Lathefixture \\
\hline 3 & & Coarse grinding & 4Grinder & 7Grinding wheel & 5Grinder fixture \\
\hline 4 & & $\begin{array}{l}\text { Semi-fine grind- } \\
\text { ing }\end{array}$ & 4Grinder & 7Grinding wheel & 5Grinderfixture \\
\hline 5 & & Fine grinding & 4Grinder & 7Grinding wheel & 5Grinderfixture \\
\hline 6 & 2 Chamfer $\mathrm{A}_{2}$ & Rough & 1Lathe & 8External Turning Tool & 4Lathefixture \\
\hline 7 & \multirow{5}{*}{$\begin{array}{l}3 \text { Cylindrical } \\
\text { surface } \mathrm{A}_{3}\end{array}$} & Rough & 1Lathe & 8External Turning Tool & 4Lathefixture \\
\hline 8 & & Semi-intensive car & 1Lathe & 8External Turning Tool & 4Lathefixture \\
\hline 9 & & \begin{tabular}{|l|} 
Coarse grinding \\
\end{tabular} & 4Grinder & 7Grinding wheel & 5Grinderfixture \\
\hline 10 & & $\begin{array}{l}\text { Semi-fine grind- } \\
\text { ing }\end{array}$ & 4Grinder & 7Grinding wheel & 5Grinderfixture \\
\hline 11 & & Fine grinding & 4Grinder & 7Grinding wheel & 5Grinderfixture \\
\hline 12 & $\begin{array}{|ll|}4 & \text { Undercut } \\
\mathrm{A}_{4} & \\
\end{array}$ & Vehicle undercut & 5Milling Machine & 9 Grooving knife & 6Milling fixture \\
\hline 13 & \multirow{2}{*}{5 Keyway $\mathrm{A}_{5}$} & Roughing & 5Milling Machine & 4 Cutter & 6Milling fixture \\
\hline 14 & & Precision milling & 5Milling Machine & 4 Cutter & 6Milling fixture \\
\hline 15 & \multirow{6}{*}{$\begin{array}{l}6 \text { Cylindrical } \\
\text { surface } \mathrm{A}_{6}\end{array}$} & Rough & 1Lathe & 8External Turning Tool & 4Lathefixture \\
\hline 16 & & Semi-intensive car & 1Lathe & 8External Turning Tool & 4Lathefixture \\
\hline 17 & & Coarse grinding & 4Grinder & 7Grinding wheel & 5Grinderfixture \\
\hline 18 & & \begin{tabular}{|l|}
$\begin{array}{l}\text { Semi-fine grind- } \\
\text { ing }\end{array}$ \\
\end{tabular} & 4Grinder & 7Grinding wheel & 5Grinderfixture \\
\hline 19 & & Fine grinding & 4Grinder & 7Grinding wheel & 5Grinderfixture \\
\hline 20 & & Precision grinding & 4Grinder & 7Grinding wheel & 5Grinderfixture \\
\hline 21 & $\begin{array}{|ll|}7 & \text { Undercut } \\
\mathrm{A}_{7} & \end{array}$ & Vehicle undercut & 5Milling Machine & 9 Grooving knife & 6Milling fixture \\
\hline 22 & \multirow{2}{*}{$\begin{array}{l}8 \text { Cylindrical } \\
\text { surface } A_{8}\end{array}$} & Rough & 1Lathe & 8External Turning Tool & 4Lathefixture \\
\hline 23 & & Semi-intensive car & 1Lathe & 8External Turning Tool & 4Lathefixture \\
\hline 24 & \multirow{3}{*}{$\begin{array}{l}8 \text { Cylindrical } \\
\text { surface } \mathrm{A}_{8}\end{array}$} & Coarse grinding & 4Grinder & 7Grinding wheel & 5Grinderfixture \\
\hline 25 & & \begin{tabular}{|l|}
$\begin{array}{l}\text { Semi-fine grind- } \\
\text { ing }\end{array}$ \\
\end{tabular} & 4Grinder & 7Grinding wheel & 5Grinderfixture \\
\hline 26 & & Fine grinding & 4Grinder & 7Grinding wheel & 5Grinderfixture \\
\hline 27 & 9 Chamfer $\mathrm{A}_{9}$ & Rough & 1Lathe & 8External Turning Tool & 4Lathefixture \\
\hline 28 & \multirow{5}{*}{$\begin{array}{l}10 \text { End face } \\
A_{10}\end{array}$} & Rough & 1Lathe & 6Facing tool & 4Lathefixture \\
\hline 29 & & \begin{tabular}{|l|} 
Semi-intensive car \\
\end{tabular} & 1Lathe & 6Facing tool & 4Lathefixture \\
\hline 30 & & Coarse grinding & 4Grinder & 7Grinding wheel & 5Grinderfixture \\
\hline 31 & & $\begin{array}{l}\text { Semi-fine grind- } \\
\text { ing }\end{array}$ & 4Grinder & 7Grinding wheel & 5Grinderfixture \\
\hline 32 & & Fine grinding & 4Grinder & 7Grinding wheel & 5Grinderfixture \\
\hline
\end{tabular}

